\title{
Mapping thematic roles onto syntactic functions: are children helped by innate linking rules?*
}

MELISSA BOWERMAN

Abstract

In recent theorizing about language acquisition, children have often been credited with innate knowledge of rules that link thematic roles such as agent and patient to syntactic functions such as subject and direct object. These rules form the basis for the hypothesis that phrase-structure rules are established through 'semantic bootstrapping', and they are also invoked to explain the acquisition of verb subcategorization frames (for example, Pinker 1984). This study examines two versions of the hypothesis that linking rules are innate, pitting them against the alternative hypothesis that linking patterns are learned (as proposed, for example, by Foley and Van Valin 1984). The first version specifies linking rules through paired thematicsyntactic role hierarchies, and the second characterizes them as a function of verb semantic structure. When predictions of the two approaches are drawn out and tested against longitudinal spontaneous speech data from two children learning English, no support is found for the hypothesis that knowledge of linking is innate; ironically, in fact, the children had more trouble with verbs that should be easy to link than with those that should be more difficult. In contrast, the hypothesis that linking rules are learned is supported: at a relatively advanced age, the children began to produce errors that are best interpreted as overregularizations of a statistically predominant linking pattern to which they had become sensitive through linguistic experience.

\section{Introduction}

Both within and across languages, there are strong regularities in the relationship between thematic roles such as agent and theme and syntactic roles such as subject and direct object. For example, if a verb has an argument that specifies an agent, this argument is assigned the properties 
of sentence subject in the vast majority of languages. Characterizations of such thematic-syntactic correspondences are often called 'linking rules'. In recent years, efforts to account for cross-linguistic consistencies in the mapping between semantics and syntax have led to speculation that linking rules reflect properties of children's innate capacity for language acquisition.

If children do have preknowledge of likely associations between thematic and syntactic roles, this would have important consequences for a theory of language acquisition, since we could appeal to this knowledge for help in accounting for how other aspects of language are learned. Two interesting appeals of this type have been made. First, Pinker (1984), Berwick (1985), and others have hypothesized that children draw on inborn knowledge of linking rules in acquiring phrase-structure rules. According to this proposal, knowledge that there are syntactic functions like subject and direct object is innate (as is knowledge of lexical and phrasal syntactic categories like N, V, NP, and VP). The child's major problem in setting up phrase-structure rules is to determine WHICH ELEMENTS of the input strings instantiate these various syntactic functions and categories. To accomplish this, the child draws on typical correspondences between semantics and syntax. For example, to learn the positioning and other properties of subjects in his language, the child looks for constituents that specify agents, since, according to the child's innate grasp of linking, these are most likely to be subjects. This account of the acquisition of phrase-structure rules has been made familiar by Pinker (1984) under the rubric 'semantic bootstrapping'.

In a second kind of appeal, innate linking rules have been invoked to help account for how children acquire the subcategorization frames of verbs and other predicates. If children have preknowledge of likely associations between thematic roles and syntactic functions, they do not have to learn the syntactic mapping of every predicate from scratch. When they learn a new predicate, they can determine the semantic functions of its noun arguments on a nonlinguistic basis and then assign those arguments the default syntactic treatment. Pinker (1984) has termed this process 'canonical mapping' (see also Levin 1985).

It is clear that an innate knowledge of linking rules would give children an enormous head start in language acquisition. Not only would it facilitate the establishment of phrase-structure rules and greatly reduce the amount of arbitrary information that would have to be learned in acquiring predicates, but it might ease the acquisition of other aspects of grammar as well (for example, Nishigauchi 1984 argues for a thematichierarchy approach to control relations). Precisely because the hypothesis that linking rules are innate buys a great deal for a theory of language 
acquisition, it is important to scrutinize it closely. In the following, I will examine two approaches to the characterization of linking rules, testing the hypothesis that knowledge of such rules is innate against empirical data from two children learning English. I will then consider an alternative hypothesis: that typical mappings between thematic roles and syntactic functions are learned on the basis of linguistic experience.

\section{Linking rules based on thematic-syntactic hierarchies}

Pinker's (1984) account of how children would draw on linking rules conforms to the general approach to linking rules taken by a number of other investigators, including Bresnan and Kanerva (1989), CarrierDuncan (1985), Carter (1976), Givón (1984), Grimshaw (1987), Jackendoff (1972), Kiparsky (1987), and Ostler (1979) (see Jackendoff i.p. for an overview of alternative fundamental assumptions about linking). In this approach, two interrelated hierarchies are postulated, one for thematic roles and one for syntactic functions. The hierarchies assumed by Pinker (1984) are shown in Figure 1.

According to Pinker, the child first looks to see whether the predicate being analyzed has an agent argument. If it does, he assigns this argument to the first function on the syntactic hierarchy, which is subject. If it does not, he looks for the next available role on the thematic hierarchy and assigns it to subject. Once subject is linked, the child moves along the thematic hierarchy to the next role associated with the predicate, say, theme/patient or goal, and assigns it to the next available syntactic function, direct object. (For some verbs the directobject function is bypassed and the second thematic role is assigned to oblique object instead.) If the predicate has still another thematic role after direct object has been linked, it is assigned to the next syntactic function, oblique object.

These are the canonical or default mappings; they apply in the absence of information to the contrary. But some predicates or constructions assign thematic roles to syntactic functions NONCANONICALLY. The paired thematic and syntactic hierarchies are set up in such a way that canonical

Grammatical functions:

$$
\text { SUBJECT }
$$

OBJECT

OBLIQUE OBJECT

Thematic roles: AGENT 
and noncanonical mappings can be distinguished on the basis of whether the links between thematic roles and syntactic functions cross. If the links do not cross, the mapping is canonical, as illustrated in Figure 2. If they do cross, the mapping is noncanonical, as shown in Figure 3. Children have to learn each noncanonical mapping by observing how fluent speakers treat the predicate syntactically (Pinker 1984: 300). What is acquired can be characterized as a 'preassociation' or 'stipulation' of the correct linking for this verb, which blocks the default application of canonical linking (Carrier-Duncan 1985; Grimshaw 1987).

\subsection{Lack of consensus about the linking hierarchies}

One obvious difficulty for the theory of linking rules just outlined is that linguists do not fully agree on what constitutes the canonical mapping between thematic and syntactic functions. For example, while Pinker (1984), Carrier-Duncan (1985), Givón (1984), and Kiparsky (1987) place theme before location/goal/source on the thematic hierarchy, Grimshaw (1987) and Jackendoff (1972) assume the reverse ordering, and Bresnan and Kanerva (1989) place recipient (a subtype of goal for many theorists) before theme but location after it.

A related problem is that although there is widespread consistency across languages about the linking at least of agents and patients which might be sufficient for the semantic bootstrapping of phrase-

1.

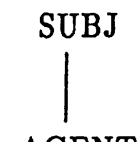

OBJ

OBLIQUE

AGENT<smiles>C[AsH2]</smiles>

THEME/PATIENT

LOCATION/GOAL/SOURCE

Johnny pushes the wagen

(AGENT)

(PATIENT)

2.
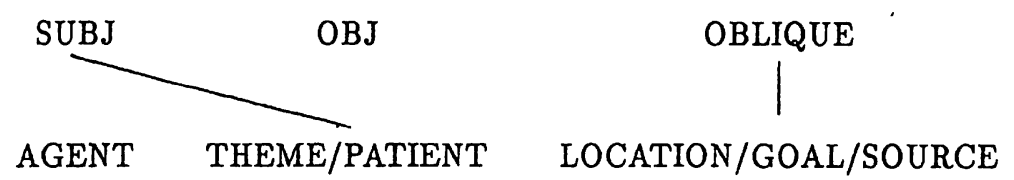

The box was/stayed in the cupboard (THEME)

(LOCATION)

Figure 2. Canonical mappings 
1.

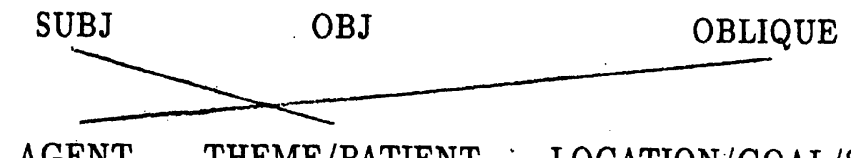

AGENT THEME/PATIENT - LOCATION/GOAL/SOURCE

The wagon was pushed by Johnny

(PATIENT)

(AGENT)

$\begin{array}{lll}\text { 2. SUBJ } & \text { OBJ } & \text { OBLIQUE } \\ \text { AGENT } & \text { THEME/PATIENT } & \text { LOCATION/GOAL/SOURCE }\end{array}$

John has a book

(LOCATION) (THEME)

John $\left\{\begin{array}{c}\text { received } \\ \text { got }\end{array}\right\}$ a book

Figure 3. Noncanonical mappings

structure rules to take place - this consistency may not be universal. Languages that have been characterized as syntactically ergative, such as Dyirbal (Dixon 1972), constitute the major candidate exceptions, since, by hypothesis, they link the patient to the subject position and the agent to the object position (Marantz 1984). These languages are rare, so innate linking rules that associate agents with subject would work for most children, but it seems implausible that children's language-acquisition device would have properties that actually MISLEAD some children about the structure of their language. ${ }^{1} \mathrm{~A}$ further related issue is whether constructs like 'subject' are in fact applicable to all languages (for example, Foley and Van Valin 1984).

Because of these and other problems, some linguists have argued that there is no cross-linguistically consistent relationship between thematic and syntactic roles (for example, Foley and Van Valin 1984; Rosen 1984). If not, a child clearly would not be able to draw on linking rules in setting up phrase-structure rules and subcategorization frames for verbs. However, linking regularities within a particular language might still be strong enough that a child could LEARN them. For example, Foley and Van Valin (1984) propose that children have to determine on the basis of linguistic experience whether agents, for example, are to be treated as 
subjects, as in English, as objects, as in Dyirbal, or, in more complicated scenarios, as neither. ${ }^{2}$ This hypothesis is compatible - as the innatelinking-rule hypothesis of course is not - with earlier proposals by Bowerman (1973), Braine (1976), Brown (1973), and Schlesinger (1971) that children do not know anything about subjects and objects in the beginning but first crack into syntax by learning how to position words that perform semantic roles like agent and patient.

\subsection{Identifying the arguments of a verb}

A second problem with the hypothesis that children have innate knowledge of thematic-syntactic linking hierarchies like those shown in Figure 1 has to do with how the child constructs the basic conceptual argument structure of a verb, or what is sometimes called its 'lexical conceptual structure' (see Levin 1985). Before a child can refer to her linking hierarchies, if she has them, to decide how to handle the arguments of a predicate syntactically, she has to know how many arguments the predicate has and what their thematic roles are. Proponents of innate linking rules have typically assumed that children arrive at this understanding through their cognitive ability to analyze the concrete situations in which they hear a verb used (for example, Berwick 1985; Pinker 1984). For instance, when they hear the verb hit, they see someone performing an action, say, Johnny, and someone or something getting acted upon, say, Tommy, and they simply assign the thematic role of agent to the former participant and that of patient to the latter. It seems very straightforward.

However, as work on lexical semantics has progressed over the last few years, it has become increasingly clear that there are important crosslinguistic differences in the argument structure of the predicates that a child would hear in a given context, say, a hitting context. For example, in English, the patient of hit - the argument that becomes the direct object - is usually the NP specifying the person or thing contacted, that is, the goal. The NP specifying the instrument - for example, a fist or a stick - is not an argument of the verb at all, so linking rules do not apply to it. If the speaker wants to refer to the instrument, she tacks on an adjunct such as 'with a stick'. In the North Caucasian language Chechen-Ingush, in contrast, the NP specifying the instrument not only is an argument of the verb meaning hit, but it is THE argument that must become the direct object; the rough rendering Johnny hit a stick to Tommy gives the idea (Nichols 1984).

This arrangement does not violate the linking-rule hierarchies shown in Figure 1. The stick can be viewed conceptually as a theme, yhich 
moves toward a goal, Tommy, and since theme precedes goal in the thematic hierarchy, no links are crossed, as shown in Figure 4a. However, the problem for the child is to determine whether the NP referring to the instrument of hitting is or is not an argument of the verb. If it is, as in Chechen-Ingush, the linking rules assign it the role of direct object; if it is not, as in English, the rules assign the role of direct object to the goal, as in Figure $4 b$.

It might be tempting to argue that the child could identify the arguments of hit by observing which NPs are subcategorized by the verb in adult speech, and then apply her innate linking rules to map these arguments to syntactic positions. But this is circular: we cannot claim that children use innate linking rules to assign syntactic functions to a particular verb's arguments, while at the same time assuming that they must refer to the verb's syntactic structure in order to identify its arguments.

However, we could maintain the hypothesis that linking rules are innate by assuming that ambiguous cases like this are acquired in the same way as noncanonical mappings - that is, that children simply learn their syntactic handling directly from the input. Linking rules would still be used, but only with other, more clear-cut predicates.

4a. Chechen-Ingush (based on Nichols 1984)

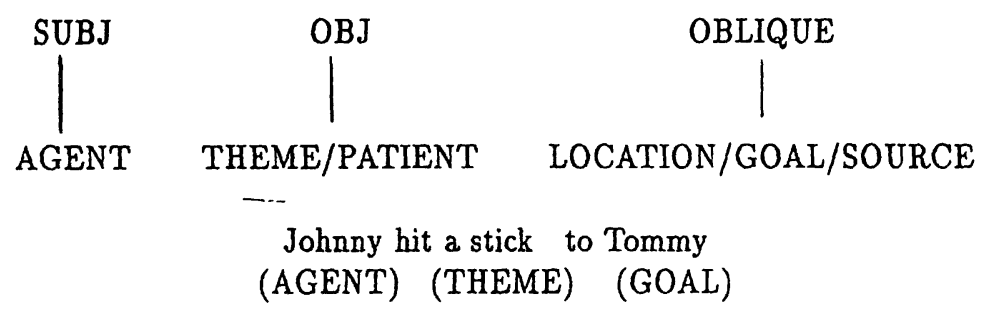

4b. English

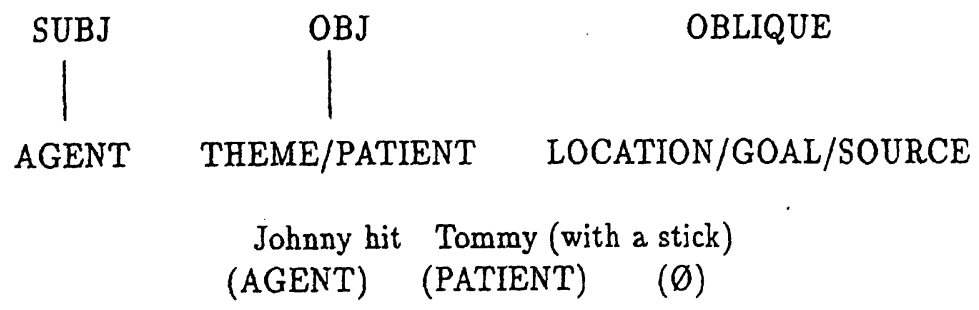

Figure 4. Contrasting mappings in Chechen-Ingush and English 
This solution is only appealing as long as the overall number of noncanonical and 'ambiguous' predicates to be learned is limited relative to the number of predicates about which the linking rules can make correct and clear-cut predictions. As the proportion of exceptions mounts, the benefits to be reaped from innate linking rules diminish and the idea becomes less plausible. Unfortunately for the hypothesis, there are many predicates whose argument structures are ambiguous when viewed in cross-language perspective. For example, the problem associated with hit affects a large number of other verbs with possible goal and instrument/ theme arguments; these include strike, cover, cut, and fill, all of which behave like hit in Chechen-Ingush and differently from the way they behave in English. Other verbs present other kinds of cross-linguistic differences in argument structure with consequences for linking (see, for example, Guerssel et al. 1985).

Even within a language there is ambiguity. For instance, although the instrument of hitting is not construed as an argument of the English verb hit when the goal is animate, it may be construed in this way when the goal is inanimate; compare *Johnny hit a stick to/against Tommy with Johnny hit a stick against the fence. (Note that cover, cut, and fill do not allow this alternative treatment in English.) Ironically, some verbs with within- and across-language argument-structure ambiguities have often been regarded as prototypical agent-patient predicates - that is, as predicates to which innate linking rules should apply in a maximally straightforward way; hit is a case in point.

\section{Testing the hypothesis that linking hierarchies are innate}

\subsection{Predictions of the hypothesis}

In sections 2.1 and 2.2 I have raised doubts on theoretical grounds about whether children are helped in acquiring language by innate knowledge of linking hierarchies. Ultimately, however, arguments either for or against the hypothesis must be backed up by concrete evidence concerning whether learning is facilitated in the hypothesized way. What kind of evidence might we look for? Pinker (1984) suggests the following possible lines of inquiry:

1. How do children treat the arguments of novel verbs, such as verbs that they make up from nouns, for which they have never heard a syntactic frame modeled?

2. How do children treat the arguments of nonsense verbs introduced by an experimenter for novel actions, events, etc.? 
3. How do children deal with legitimate verbs of their language that have noncanonical mappings?

I agree in principle that novel verbs and nonsense verbs are a place to look for evidence of innate linking rules. Children do generally treat such verbs in the canonical way, as Pinker (1984) points out. But the evidence available so far cannot be interpreted as favoring the innate-linking-rules hypothesis. The problem is that by the time children start producing novel denominal verbs (for example broom = 'sweep') and the like, they are usually at least several months past the early stages of word combination. This means that even if they didn't start out with any knowledge of linking rules, they have had time to LEARN the most typical associations between thematic and syntactic roles, such as agent before verb, patient after verb (as Pinker himself [1984: 58] in fact recognizes). This is even more true for children taught to produce or understand nonsense verbs in an experiment, as in, for example, Marantz (1982), since they are usually at least three or four years old. This means that evidence from children's syntactic treatment of novel verbs and nonsense verbs is ambiguous: it is compatible with both the hypothesis that linking rules are innate and the hypothesis that they are learned.

This leaves us with children's treatment of the noncanonical verbs of their language. The most straightforward prediction is that if children rely on innate rules in the early stages of syntactic and lexical development, they should tend to make what we could call 'default mapping errors' with noncanonical verbs - for example, reversing the subject and object of verbs like receive or have, which have goal or location subjects and theme objects (see Figure 3).

Mapping errors like these have not been attested in the early period of language acquisition. However, Pinker (1984) argues that this is not telling evidence against the linking-rule hypothesis. He points out that children cannot rely ONLY on canonical mapping in acquiring verbs, since otherwise they could never learn noncanonical verbs. They therefore also have to be able to learn through positive, distributional evidence - that is, to pay attention to the way the noun arguments of particular verbs are treated in the speech of fluent speakers. Pinker proposes that this mechanism - positive distributional learning - must be allowed to OVERRIDE canonical mapping so that preassociations for noncanonical verbs can be learned; this is why we needn't expect default mapping errors for verbs heard in the input.

This argument seems to me somewhat doubtful, since it is well known that children make 'default errors' of many other kinds, even though they have had ample opportunity to learn the correct constructions

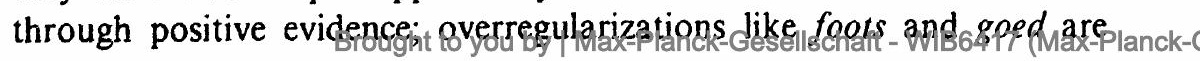


cases in point. However, even if for the sake of argument we agree that the atsence of initial mapping errors with non-canonically linked verbs is still compatible with the hypothesis that children draw on innate linking rules, we can certainly predict that it should TAKE LONGER for children to learn the correct syntactic treatment for the arguments of noncanonical verbs than canonical verbs. The reasoning is as follows.

For canonical verbs, the evidence coming from the input about the syntactic treatment of the verb's arguments MATCHES the child's innate linking rules. There is no conflict, so evidence from the input and innate dispositions sum to facilitate acquisition (see also Pinker 1984: 59-60). For noncanonical verbs, in contrast, there is conflict: the child's linking rules say to do one thing, and the input says to do another. The child has to attend to the input to preassociate thematic roles with the correct syntactic roles so that canonical mapping will not apply. This means that acquisition should take longer.

Reasoning in this way, Pinker (1984) suggested that the innate-linkingrules hypothesis is supported by the fact that noncanonical verbs like receive appear very late in children's speech, as do passives, which reverse the canonical arrangement of agent and patient (see Figure 3). But this argument is weak because there is another highly plausible reason why these forms may be late: they are exceedingly rare in the input to children. What we need is evidence concerning the relative time at which canonical versus noncanonical predicates of a certain type are learned when ВОTH alternatives are modeled to roughly the same extent in the input.

In the input to young children learning English there are in fact a few frequently modeled verbs that are noncanonical according to the paired thematic-syntactic hierarchies shown in Figure 1. These include have, get (in the sense of receive), and got (either as the past tense of get [= received] or in the sense of ' $I$ ['ve] got X'; children frequently omit the auxiliary and treat got as a present-tense form equivalent to have). These verbs involve locative or goal subjects and theme direct objects, as was shown in Figure 3. Another frequently modeled noncanonical pattern is the double-object construction with verbs of giving and communication, as in John gave Mary a book. Here, the recipient or goal argument (Mary) is assigned to the direct-object position even though the theme argument, book, is higher on the thematic-role hierarchy. (In the prepositional counterparts of double-object constructions, as in John gave a book to Mary, mapping is canonical.) Do children master the syntactic mapping of these noncanonical verbs and constructions more slowly than the mapping of their canonical counterparts? If so, this would be evidence for the influence of innate linking rules.

There is a complication for a straightforward test of this question: as 
mentioned earlier, theoreticians disagree about the relative position of theme vs. location/goal/source on the thematic hierarchy. Whereas for Pinker (1984) and Carrier-Duncan (1985), among others, theme is HIGHER, for Grimshaw (1987) it is LOWER. This means that which verbs or constructions are considered canonical and which noncanonical is exactly reversed for these two sets of investigators. In consequence, child-language evidence AGAINST the Pinker/Carrier-Duncan hierarchy might well be interpreted as evidence IN FAVOR of the Grimshaw hierarchy. The only patterns of acquisition that would unequivocally challenge both hierarchies - and hence the larger hypothesis that languagelearning children make use of such hierarchies - would be either for the syntactic treatment of verbs/constructions of the two types to be established simultaneously, or for verbs/constructions of one type to be mastered earlier by some children and verbs/constructions of the other type by other children.

With these considerations in mind, I have investigated the syntactic handling of verbs with theme and location/goal/source arguments in the language development of my two English-speaking daughters. The data examined consist of longitudinal diary records. Although these data were not collected with such an analysis in mind, they are ideally suited to it. A chronic problem for investigators who want to examine the development of verb-argument structure in children's spontaneous speech is that most speech corpora are not dense enough to allow the syntactic behavior of INDIVIDUAL VERBS to be followed in detail. However, at the time I recorded my daughters' speech, I was interested in the possible semantic underpinnings of early syntax (as proposed in Bowerman 1973), and I was determined to note things down in sufficient detail that $I$ would be able to trace the history of every verb as it began to come into combination with subjects, objects, and other constituents (see Bowerman 1976). As a consequence, my records for the early period of sentence construction are very rich.

\subsection{Verbs with theme and location/goal/source arguments}

We look first at how the children approached verbs with two associated thematic roles, one a theme specifying a moving or located object, and the other a location, goal, or source (L/G/S) argument specifying the location, endpoint, or starting point of the event named by the verb. For some verbs, the theme is the subject and the $\mathrm{L} / \mathrm{G} / \mathrm{S}$ argument is the direct or (optional) oblique object; examples include stay, come, live [somewhere], and be [at a location]. To avoid taking a standing on which 
arrangement is canonical, let us simply call them theme-subject verbs. ${ }^{3}$ For other verbs, the location, goal, or source argument is the subject and the theme is the direct object; examples include have, get (in the sense of receive), got (in the sense of have or received), and lose (lose has a source subject; see Carrier-Duncan 1985: 2 on lose). We will call these L/G/Ssubject verbs.

Is there evidence that children map the arguments of theme-subject verbs to their appropriate syntactic functions earlier than the arguments of $\mathrm{L} / \mathrm{G} / \mathrm{S}$-subject verbs, or vice versa? For children learning English, the earliest-learned and most important property of the syntactic functions subject and direct/oblique object is the way they are ordered with respect to the verb, so I will consider the correct ordering of arguments in the children's speech as diagnostic of correct mapping.

Strictly speaking, only utterances containing BOTH a theme and a L/G/S argument are relevant to the linking-rule hypothesis. This is because noncanonicality is defined in terms of crossed links on the paired thematic and syntactic hierarchies, as discussed earlier, and links cannot cross unless the verb appears with at least two noun arguments. However, it is also worth noting how children handle these verbs with a single argument in the period before they produce two-argument strings.

Not every child utterance with a theme-subject or L/G/S-subject verb can be used in this analysis. Many utterances must be excluded because the child might have mapped the arguments on the basis of the wrong kind of thematic information for our purposes. Two-argument utterances with theme-subject verbs like come, stay, and sit were excluded if the theme was an animate entity that could also be construed as an agent (for example, 'Mommy come house'), since the mapping of such themes might be accomplished by reference to a linking rule that applies to agents rather than themes. Two-argument utterances with $L / G / S$-subject verbs were excluded if they occurred in a context in which the child might have had an agentive meaning in mind, for example, ' $I$ get $X$ ' while seizing something (= take) and ' $\mathrm{I}$ have $\mathrm{X}$ ' while either grabbing something $(=t a k e)$ or in the context of meals or snacks (=eat/drink; as in 'I'm having a cookie'). Also excluded were uses of have with idiomatic direct objects, for example, '... have a bath/a B.M.' and all utterances (1) whose intended referent event was unclear, (2) which were direct imitations of adult utterances in the preceding dialogue, (3) which followed an adult use of the verb in which the conventional order of theme and $L / G / S$ constituents was modeled, even though with different NPs from those in the child's utterance, or (4) which were self-repetitions.

The number of utterances that remain after all this sifting is not large, but the sample is 'pure' from the standpoint of the hypothesis to be 
tested. The data from Christy are charted in Figure 5 and from Eva in Figure 6.

In the left panel of each chart are shown utterances with theme-subject verbs, and in the right panel those with $\mathrm{L} / \mathrm{G} / \mathrm{S}$-subject verbs. Data from successively later age periods are presented in a downward direction, from the first period within which any strings of the relevant type were recorded (summary displays of single-argument utterances are discontinued after two-argument strings emerge). For ease of display, the data are collapsed into two-week intervals, except at a critical point for each child when a finer breakdown is needed. Misordered strings (produced only by Eva) are shown below a dotted line in the relevant cells. Context notes give information relevant to utterances that need disambiguation or whose classification is especially sensitive.

What do these charts reveal about the relative ease of learning the syntactic mapping of theme-subject vs. L/G/S-subject verbs? Looking first at Figure 5 (Christy) we see that evidence for productivity across verbs begins with the onset of two-argument strings at age 1;9 (week 4). ${ }^{4}$ Remarkably, within a four-day period during this week Christy began to produce вотн theme-subject and L/G/S-subject verbs with two arguments, ordered appropriately and in the opposite way. From this point on, the two verb patterns develop in parallel. This is a striking coincidence in timing of emergence, as researchers who have worked with longitudinal data will recognize.

Turning to Figure 6 (Eva), we see a very similar pattern of development. Before utterances consisting of a verb plus two arguments come in, there are more instances of verbs with a single argument than in Christy's case. However, word order is unstable and both theme-subject and L/G/Ssubject verbs are represented. Most remarkably - exactly as for Christy - both theme-subject and L/G/S-subject verbs began to combine with two appropriately ordered arguments in the same week (1;8 [week 4]), and in fact within TWO DAYs of each other, and from this point they developed in parallel. Unlike Christy, Eva made a few ordering errors in two-argument strings, but these involve only two verbs (one from each pattern: come from theme-subject and have from L/G/S-subject), and in both cases there is clearly linguistic input that could have motivated the errors. 5

These data provide no support for the hypothesis that children receive selective help from innate linking rules for verbs of one type over verbs of the other type. When we compare theme-subject verbs taken as a group to $\mathrm{L} / \mathrm{G} / \mathrm{S}$-subject verbs as a group, we find that the degree of difficulty children experience in assigning thematic roles to syntactic functions is equal. 


\begin{tabular}{|c|c|c|}
\hline Age $^{2}$ & Theme subject & Location/Goal/Source subject \\
\hline $\begin{array}{l}1 ; 9 \\
\text { weeks } \\
1 \& 2\end{array}$ & $\begin{array}{l}\text { [ONE-ARGUMENT C } \\
X \text { fall (down) (5) } \\
\text { fall down daddy }<=\text { on daddy }>\end{array}$ & [NATIONS BEGIN] \\
\hline $\begin{array}{l}1 ; 9 \\
\text { week } \\
3\end{array}$ & fall down $X<=$ on $X>$ (2) & have a new record \\
\hline $\begin{array}{l}1 ; 9 \\
\text { week }\end{array}$ & [TWO-ARGUMENT C & INATIONS BEGIN] \\
\hline 4 & $\begin{array}{l}\text { baby fall down daddy } \\
\text { shirt }<=\text { on }>b \\
\text { baby fall down me }<=\text { on }> \\
\text { dolly stay home } \\
\text { toy stay home }\end{array}$ & $\begin{array}{l}\text { cow have ice } \\
\text { daddy have cake }^{\mathrm{d}} \\
\text { I got water } \\
\text { I get spoon } \\
\text { I-want get more }\end{array}$ \\
\hline $\begin{array}{l}1 ; 10 \\
\text { weeks } \\
1 \& 2\end{array}$ & ------- & wow-wow wear bracelet ${ }^{i}$ \\
\hline $\begin{array}{l}1 ; 10 \\
\text { weeks } \\
3 \& 4\end{array}$ & bottle spill floor & I got pen ${ }^{j}$ \\
\hline $\begin{array}{l}1 ; 11 \\
\text { weeks } \\
1 \& 2\end{array}$ & coat stay home & $\begin{array}{l}\text { Christy have wow-wow } \\
\text { Christy get egg } \\
\text { Christy forgot milk }\end{array}$ \\
\hline $\begin{array}{l}1 ; 11 \\
\text { weeks } \\
3 \& 4\end{array}$ & $\begin{array}{l}\text { daddy stay here, not airplane } \\
\text { dolly coming Christy birthday } \\
\text { cake? }<=\text { to C's b'day party }>\end{array}$ & $\begin{array}{l}\text { swing haven't a mouth } \\
\text { this boy have hat } \\
\text { daddy have cake no } \\
\text { I got baby } \\
\text { mommy lost button }\end{array}$ \\
\hline $\begin{array}{l}2 ; 0 \\
\text { weeks } \\
1 \& 2\end{array}$ & $\begin{array}{l}\text { we're in (the?) car } \\
\text { balloon was outside } \\
\text { other wow-wow outside... } \\
\text { was outside } \\
\text { my big dolly sit down } \\
\text { daddy car }<=\text { in }> \\
\text { I didn't fall down water } \\
\text { I not fall down head } \\
\text { BM coming birdie fanny }{ }^{\mathfrak{t}}<=\text { from }>\end{array}$ & $\begin{array}{l}\text { I have peas already } \\
\text { bear have some mine } \\
\text { I got breakfast this cup } \\
\text { daddy wear a bib no... } \\
\text { mine }<=\text { I }>\text { wear a bib } \\
\text { I lost other blanket }\end{array}$ \\
\hline
\end{tabular}




\section{Notes}

a. 1;9 [weeks 1\&2] indicates the first half-month after age 1 year, 9 months has been reached. Numbers in parentheses indicate frequencies of combinations beyond one; selfrepetitions not counted. In context notes, $\mathrm{C}=\mathrm{Christy}, \mathrm{E}=\mathrm{Eva}, \mathrm{M}=$ Mother, $\mathrm{F}=$ Father.

b. Doll has just toppled onto F's shirt, on the table.

c. $C$ has just requested ice for toy cow; now following $M$ into kitchen as $M$ goes to get it.

d. Bringing piece of cake to $F$.

e. Showing $\mathrm{F}$ a glass of water that $\mathrm{M}$ has just given her.

f. Taking spoon that $\mathrm{M}$ hands to her.

g. Wants to continue game where she drops spoon from highchair, $M$ returns it.

h. Looking at pancakes on M's plate. $M$ is not eating. F has just said pancakes were warm.

i. Putting bracelet on toy dog's paw.

j. To a friend on the phone, as she sits holding and playing with pens.

k. Holding toy dog.

1. Anticipating her morning egg, which $\mathrm{M}$ is fixing and will give to her.

m. Coming back to retrieve a glass of milk she'd left behind.

n. After $M$ asks if her swing will eat some birthday cake.

o. Looking at a picture of a boy with no hat on. $\mathrm{C}$ often uses 'have' to mean 'don't have'.

p. Everyone but $\mathrm{F}$ has cake.

q. Holding her doll in the tub.

r. Offering something to her bear.

s. Showing $F$ that she has gotten 'Instant Breakfast' in the cup she wanted.

t. Imagining droppings coming from a bird's bottom.

Figure 5. Syntactic mapping of verbs with theme and location/goal/source arguments in Christy's speech

\subsection{Three-argument verbs with recipient or beneficiary goals}

The conclusion that canonically linked verbs are no easier for children than non-canonically linked verbs (however canonicality is defined) is also supported by analyses of these children's acquisition of verbs like give, bring, and show, which have an agent subject and allow either the item transferred or shown (theme) or the recipient (goal) to be direct object. (To these we may add constructions with 'for' beneficiaries with verbs like make, relevant only for Eva). One child, Eva, acquired both patterns more or less simultaneously, although she favored the theme-asdirect-object mapping (with the goal NP introduced by a preposition), as the linking-rule hypothesis (version shown in Figure 1) would predict. ${ }^{6}$ In contrast, the other child, Christy, clearly favored the double-object or goal-as-direct-object mapping. The data from Christy are shown in Figure 7, and from Eva in Figure 8. (As in Figures 5 and 6, self-repetitions and direct and partial imitations are excluded from the analysis.) 


\begin{tabular}{|c|c|c|}
\hline & Theme subject & Location/Goal/Source subject \\
\hline $1 ; 8$ & \multicolumn{2}{|c|}{ [ONE-ARGUMENT COMBINATIONS BEGIN] } \\
\hline $\begin{array}{l}\text { wecks } \\
1 \& 2\end{array}$ & $\begin{array}{l}\mathrm{X} \text { go? < where did X go > (4) } \\
\text { beary go, X stay (4), X fit } \\
\text { Ernie fell off, beary come off } \\
\text { stay daddy, stay mommy } \\
\quad<=\text { stay with F, M > }\end{array}$ & gots bottle \\
\hline & $\begin{array}{l}\text { fall baby (VS) } \\
\text { stay home baby (VOS) }\end{array}$ & baby got $(\mathrm{OV})$ \\
\hline $\begin{array}{l}1 ; 8 \\
\text { week } \\
3\end{array}$ & $\begin{array}{l}\text { I fall } \\
\text { fit } X<=\text { into } X>\text { (2) } \\
\text { drip plate }<=\text { on }> \\
\text { Ernie fit }<=\text { fit into Ernie }>\end{array}$ & $\begin{array}{l}\text { have milk, daddy? }<=\text { will you... } \\
\text { have cookie }<=\text { I have... }>\end{array}$ \\
\hline $1 ; 8$ & \multicolumn{2}{|c|}{ [TWO-ARGUMENT COMBINATIONS BEGIN] } \\
\hline $\begin{array}{l}\text { week } \\
4\end{array}$ & necklace stay purse $\mathrm{e}^{\mathbf{a}}$ & $\begin{array}{l}\text { Ernie got spoon } \\
\text { I got necklace }\end{array}$ \\
\hline $\begin{array}{l}1 ; 9 \\
\text { weeks } \\
1 \& 2\end{array}$ & $\begin{array}{l}\text { Andrea stay Mary }<=\text { with }^{\text {M. }}> \\
\text { my poppy tangle pumpkin } \\
\end{array}$ & \\
\hline $\begin{array}{l}1 ; 9 \\
\text { weeks } \\
3 \& 4\end{array}$ & $\begin{array}{l}\text { pumpkin stay my suitcase } \\
\text { mommy stay me }<=\text { with me }> \\
\text { boys come out my bag } \\
\text { yukkie came off my dipie } \\
\text { steam coming out my mouth } \\
\text { comen......................... } \\
<=X \text { comes to } M>\end{array}$ & Tasha have it ${ }^{\mathrm{f}}$ \\
\hline $\begin{array}{l}1 ; 10 \\
\text { weeks } \\
1 \& 2\end{array}$ & $\begin{array}{l}\text { beads came off my necklace } \\
\text { raining coming down my coat } \\
\text { raining coming down my head } \\
\text { I tangle up Andrea's } \\
\text { h } \\
\text { no.................. } \\
\text { no bobidi fanny comes } \\
<=\text { no B.M. comes from... }>\end{array}$ & $\begin{array}{l}\text { I got some. You got some. } \\
\text { Christy got some }{ }^{\mathrm{j}} \text {. <M: some } \\
\text { what? E: earsies }> \\
\text { daddy have butter } \\
\text { I have some. you have some. } \\
\text { Christy have some } \mathrm{e}^{1} .<\mathrm{M} \text { : some } \\
\text { what? E: hair }>\end{array}$ \\
\hline & & \\
\hline
\end{tabular}

Figure 6 


\begin{tabular}{l|l}
$1 ; 10$ & pan live in down there \\
weeks & I'm do not falling out \\
$3 \& 4$ & my place! \\
& $\begin{array}{l}\text { daddy's cake was in there } \\
\text { I want be up there }\end{array}$
\end{tabular}

I don't have froggie in my purse you don't have your hat you have two clothes I want...you have bottle $<=$ want you to have... $>$

have Christy vitamin pill? ${ }^{\text {(VSO) }}$

\section{Notes}

a. Giving her necklace to $M$ to keep in M's purse, as $M$ and $E$ leave house.

b. Holding a spoon against the hand of Ernie, a puppet.

c. Holding out a necklace she's wearing to show clerk in store.

d. When $\mathrm{E}$ finds her pacifier < = poppy > tangled in handle of her pumpkin basket.

e. Said when $\mathbf{E}$ discovers her pumpkin basket in a suitcase; $\mathbf{M}$ has told her to leave it there.

f. When M put E's leftover food in dog's (Tasha's) dish.

g. 'Raining' is E's standard word for 'rain'.

h. < = I'm tangled up in Andrea's chair >. E can't get out of her chair because chair Andrea is sitting in is pushed up against it.

i. After sitting unsuccessfully on the potty. 'Bobidi' is E's word for B.M.

j. Looking at $\mathrm{C}$, who is wearing a headpiece with rabbit ears.

k. F has butter; $E$ has just asked where her butter is.

1. Watching $M$ brush C's hair.

$\mathrm{m}$. Holding pot lid and pointing to drawer under stove where pans are kept.

n. 'Will $\mathrm{C}$ have a vitamin pill'?

Figure 6. Syntactic mapping of verbs with theme and location/goal/source arguments in Eva's speech

Once again, then, the predicted systematic difference between constructions of the two kinds is absent.

\subsection{Agents and patients}

At this point, a proponent of the theory that children have unlearned knowledge of thematic-syntactic linking hierarchies might argue as follows: 'It's true that the results don't look good for the hypothesis that children have an innate knowledge of default mappings of theme and location/goal/source arguments relative to each other. But there has been disagreement about the relative position of these roles on the thematic hierarchy anyway. Perhaps, then, there are no innate mapping predispositions for these particular roles. Children might nevertheless have preknowledge of default mappings involving OTHER thematic roles. For example, even if they onlyrdogowo bowoto maaplagentseandcpatientiganto(Max-Planck-C 


\begin{tabular}{|c|c|c|}
\hline Age & (agent) $-\mathrm{V}-$ theme - goal & (agent) $-V-$ goal - theme \\
\hline $\begin{array}{l}1 ; 9- \\
1 ; 11 \\
\text { week } \\
3\end{array}$ & & $\begin{array}{l}\text { [Only strings with 'gimme'+ } \\
\text { theme, where 'gimme' is an } \\
\text { unanalyzed unit] }\end{array}$ \\
\hline $\begin{array}{l}1 ; 11 \\
\text { weeks } \\
3 \& 4\end{array}$ & & grandma gimme Christy dolly \\
\hline $\begin{array}{l}2 ; 0 \\
\text { weeks } \\
1 \& 2\end{array}$ & & $\begin{array}{l}\text { daddy gimme mommy milk } \\
\text { I give wow-wow something eat }\end{array}$ \\
\hline $\begin{array}{l}2 ; 0 \\
\text { weeks } \\
3 \& 4\end{array}$ & $\begin{array}{l}\text { I give a nipple mommy } \\
\text { my mommy buy one for me }\end{array}$ & $\begin{array}{l}\text { I give mommy a bottle } \\
\text { my mommy give my }<=\text { me }>\text { a bottle } \\
\text { let me get down, give mommy nipple } \\
\text { I give lady money } \\
\text { give daddy black one } \\
\text { mommy give my }<=\text { me }>\text { a big bite } \\
\text { daddy give my }<=\text { me }>\text { a kiss } \\
\text { my mommy buy me dipies }<=\text { diapers }> \\
\text { lady bring us coke } \\
\text { show me clothes you make }\end{array}$ \\
\hline $\begin{array}{l}2 ; 1 \\
\text { weeks } \\
1 \& 2\end{array}$ & Benji bring it me & $\begin{array}{l}\text { grandma give Klaus a [NP] } \\
\text { I give you some more } \\
\text { where book Mudgie Ma gave me? }\end{array}$ \\
\hline
\end{tabular}

Note

a. < = Grandma give Christy dolly $>$. 'Gimme' is at this point still unanalyzed; it seems to mean simply 'give' and so combines with an indirect-object NP.

Figure 7. Syntactic mapping of verbs with agent, theme, and goal (recipient or beneficiary) arguments in Christy's speech

syntactic positions, this would still be enough to drive the semantic bootstrapping of phrase-structure rules.'

If children get help from innate linking rules for verbs with agent and patient arguments, but not for verbs with theme and location/goal/source arguments, correctly ordered agent-verb-patient strings should emerge earlier, according to the reasoning spelled out in section 3.1. To test this possibility I have determined for both my subjects the point at which verbs began to appear with agent and patient arguments, ordered appropriately.

The hypothesis that children get selective help for agent-patient verbs 


\begin{tabular}{|c|c|c|}
\hline & (agent) $-V-$ theme - goal & (agent) $-\mathrm{V}-$ goal - theme \\
\hline $\begin{array}{l}1 ; 9 \\
\text { weeks } \\
1 \& 2\end{array}$ & $\begin{array}{l}\text { read book me }<=\text { to me }>(2) \\
\text { make ring me }<=\text { for me }> \\
\text { make ring mommy }<=\text { for } M>\end{array}$ & make ring...make me ring \\
\hline $\begin{array}{l}1 ; 9 \\
\text { weeks } \\
3 \& 4\end{array}$ & 1 & $\begin{array}{l}\text { tell Christy come back } \\
\quad<=\text { tell } C \text { to come back }> \\
\text { bring Daddy plate }\end{array}$ \\
\hline $\begin{array}{l}1 ; 10 \\
\text { weeks } \\
1 \& 2\end{array}$ & lemme me read! ... to you & \\
\hline $\begin{array}{l}1 ; 10 \\
\text { weeks } \\
3 \& 4\end{array}$ & $\begin{array}{l}\text { I get that for you } \\
\text { give candy for me }<=\text { to me }> \\
\text { Christy bring that for me }<=\text { to me }> \\
\text { get towel for me }\end{array}$ & $\begin{array}{l}\text { Linda gave my }<=\text { me }>\text { choochoo } \\
\text { train } \\
\text { lemme tell Christy close door } \\
\quad<=\text { tell } C \text { to close door }>\end{array}$ \\
\hline $\begin{array}{l}1 ; 11 \\
\text { weeks } \\
1 \& 2\end{array}$ & $\begin{array}{l}\text { only get more for me } \\
\text { read book for me }(2)<=\text { to me }> \\
\text { I give my chocolate pudding Daddy } \\
\text { Christy give cards for me }<=\text { to me }> \\
\text { Santa Claus give candy to me } \\
\text { my mama buy mocking bird for me } \\
\text { Christy give my lady bug to me }\end{array}$ & $\begin{array}{l}\text { I show-me Christy artichoke } \\
\text { me go Dot house, show-me Dot my } \\
\text { bottle }{ }^{\mathrm{a}} \\
\text { I ask Daddy have my bottle... } \\
\text { I tell Daddy have my bottle } \\
<=\text { tell D that I have... }>\end{array}$ \\
\hline
\end{tabular}

Notes

a. 'Show-me' is an unanalyzed unit, meaning simply 'show'.

b. Note that $\mathrm{E}$ has transformed this into the prepositional construction; the model is the song line 'Mama's gonna buy you a mocking bird'.

Figure 8. Syntactic mapping of verbs with agent, theme, and goal (recipient or beneficiary) arguments in Eva's speech

can be tested most fairly by concentrating on clear-cut or prototypical instances of agents and patients. Including less clear-cut instances might dilute the evidence for facilitation, since children could have trouble applying their linking rules to verbs whose arguments they do not recognize as playing the roles of agent and patient. In the 'prototypical agentpatient' category I have therefore included only (1) strings expressing the causation by an agent of a change of state or location, with verbs such as open, close, break, fix, put away, throw away, and pick up, and (2) utterances with kinetic verbs expressing events in which the agent acts on the patient in a physically obvious way; for example, push, wash, bite, eat, tickle, spank, and get (in the sense of grab or take). ${ }^{7}$ 


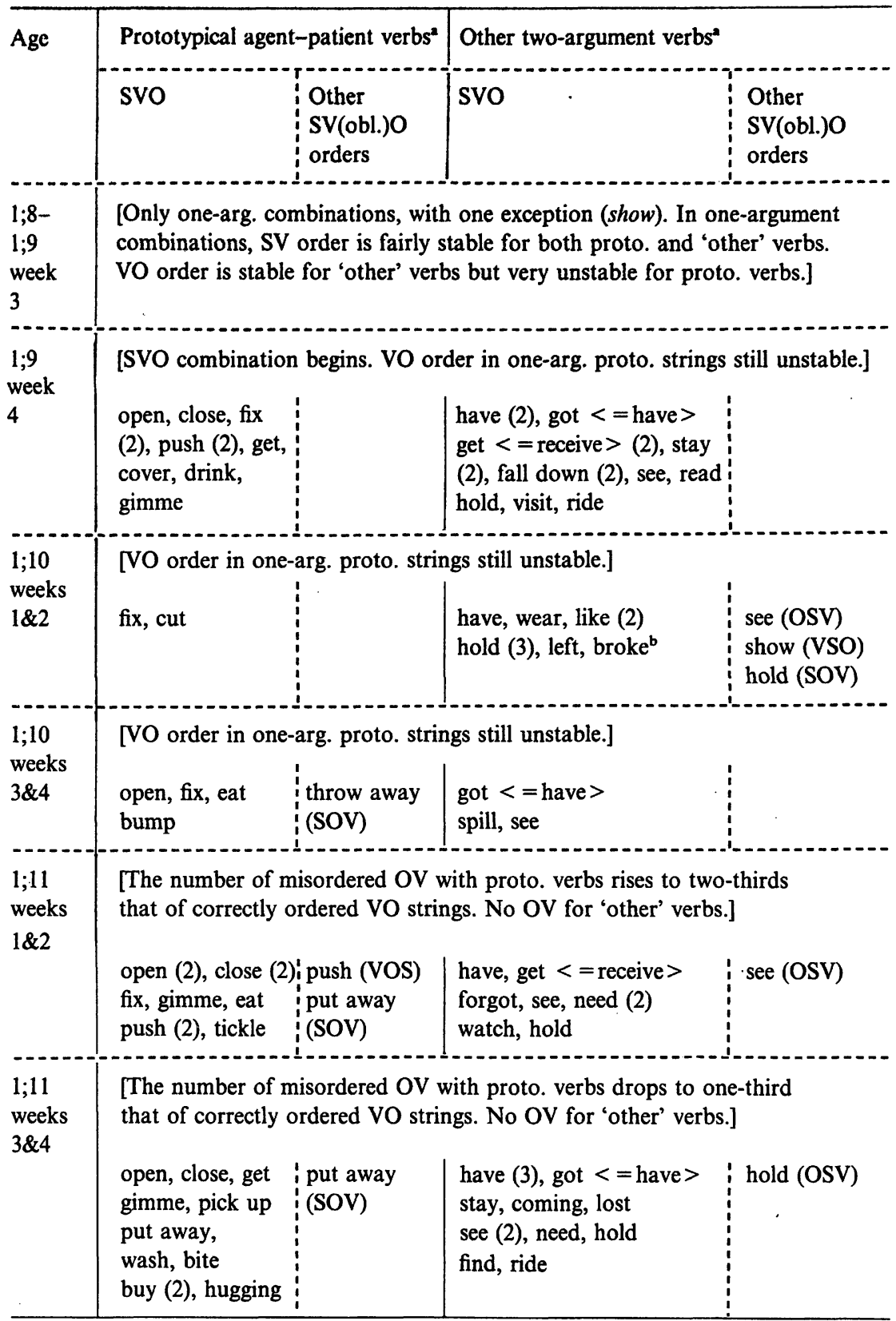

Figure 9 


\section{Notes}

a. Verbs listed represent strings with verb and two arguments, with frequencies beyond one shown in parentheses. See text for description of the verbs counted as 'Proto. agent-patient' and 'other two-argument verbs'. Behavior of one-argument strings is summarized in brackets.

b. 'Man broke face', playing with plastic man-doll whose face is chipped.

Figure 9. Syntactic mapping of verbs with prototypical agent-patient arguments vs. 'other' two-argument verbs in Christy's speech

'Prototypical agent-patient utterances' of the above types are compared with utterances involving several types of 'other two-argument verbs': (1) utterances with theme-subject verbs and location/source/goalsubject verbs (as discussed in section 3.2 and presented in Figures 5 and 6), (2) stative transitive verbs such as see, hear, like, need, scare with inanimate subject, and hurt (as in 'B.M. hurts me'), and (3) 'nonprototypical' agent-patient strings expressing events in which the agent is relatively static (such as hold, read, ride), or does not control the event (drop, spill), or does not act physically on the object (talk [to], say, look [at], scare with animate, agentive subject), or does not act on the object in any specific way (find, play [with]), or in which there is no preexisting object (draw, write, make). ${ }^{8}$ Subcategory (1) is most relevant for present purposes, but information about (2) will be important for the discussion in section 5 below, and (3) is included because its status is uncertain that is, it is unclear whether children in fact have more trouble with nonprototypical agent-patient verbs than with prototypical ones.

The results are presented in Figures 9 and 10. These are organized like Figures 5 and 6 with two exceptions: incorrectly ordered strings are shown in separate columns rather than beneath a dotted line in each ageperiod cell, and information about one-argument strings is simply summarized at points.

The question we are asking is whether correctly ordered strings expressing prototypical agent-patient relationships preceded correctly ordered strings expressing other kinds of relationships between two arguments, especially relations between a theme and a locative, goal, or source argument. This outcome would be compatible with the hypothesis that children have recourse to innate knowledge concerning how agents and patients are linked to syntactic functions but have to learn other linkages from scratch.

Looking first at the data from Christy (Figure 9), we see that twoargument utterances with prototypical agents and patients appear first at age 1;9 (week 4). This is exactly the same week in which theme-subject and $\mathrm{L} / \mathrm{G} / \mathrm{S}$-subject verbs such as stay and have were first combined with 


\begin{tabular}{|c|c|c|}
\hline Age & \begin{tabular}{l|l} 
Prototypical agent-patient verbs \\
SVO & $\begin{array}{l}\text { Other SVO } \\
\text { orders }\end{array}$
\end{tabular} & $\begin{array}{lll}\text { Other two-argument verbs } \\
\text { SV (obl.)O } & \begin{array}{l}\text { Other } \\
\text { SV(obl.)O } \\
\text { orders }\end{array}\end{array}$ \\
\hline $\begin{array}{l}\text { before } \\
1 ; 8\end{array}$ & \multicolumn{2}{|c|}{$\begin{array}{l}\text { [Occurrences of SVO limited to fixed frames like 'X do-it' and 'I verb-it'. } \\
\text { SV and VO order fairly stable up to now for both proto. and 'other' verbs.] }\end{array}$} \\
\hline $\begin{array}{l}1 ; 8 \\
\text { weeks } \\
1 \& 2\end{array}$ & \multicolumn{2}{|c|}{$\begin{array}{l}\text { [With onset of SVO strings here, one-argument SV and esp. VO word orders } \\
\text { become unstable. True of both proto. verbs and 'other verbs', but esp. } \\
\text { the former; errors continue for many weeks.] } \\
\text { get, eat }\end{array}$} \\
\hline $\begin{array}{l}1 ; 8 \\
\text { weeks } \\
3 \& 4\end{array}$ & $\begin{array}{l}\text { close } \\
\text { get, fix }\end{array}$ & $\begin{array}{l}\text { got }<=\text { have }>(2) \\
\text { stay, draw } \\
\text { write }<=\text { draw }>\end{array}$ \\
\hline $\begin{array}{l}1 ; 9 \\
\text { weeks } \\
1 \& 2\end{array}$ & \begin{tabular}{l|l} 
break, close & $\operatorname{open}^{\mathrm{c}}(2)(\mathrm{VOS})$ \\
get, take & $\operatorname{get}^{\mathrm{d}}(\mathrm{OSV})$ \\
change & , eat \\
push, pinch & $\operatorname{take}^{\mathrm{e}}(3)$ (VSO) \\
eat $^{\mathrm{f}}$ (OSV) \\
hit $^{\mathrm{g}}$ (VOS)
\end{tabular} & $\begin{array}{l}\text { stay, tangle(d) } \\
\text { look, talk, draw } \\
\text { want, play } \\
\text { pinch } \\
\text { cook, ride (5) } \\
\text { coill (2) }\end{array}$ \\
\hline $\begin{array}{l}1 ; 9 \\
\text { weeks } \\
3 \& 4\end{array}$ & $\begin{array}{l}\text { close, get } \\
\text { take, get } \mathrm{X} \text { up, } \\
\text { eat (3) } \\
\text { spank, drive }\end{array}$ & $\begin{array}{l}\text { have, stay (2) } \\
\text { come(ing) out (2) } \\
\text { came off, see (4) } \\
\text { hear, scare (3) } \\
\text { want (2), join, ride }\end{array}$ \\
\hline $\begin{array}{l}1 ; 10 \\
\text { weeks } \\
1 \& 2\end{array}$ & $\begin{array}{l}\text { [SVO order stabilizes now, errors beco } \\
\text { open (2) } \\
\text { close (2) } \\
\text { fix (2) get (2) } \\
\text { take (2), give (2) } \\
\text { take away } \\
\text { get up < = pick up> } \\
\text { get X on, eat (5) } \\
\text { push, carry, wash } \\
\text { pinch (2), kick } \\
\text { snapping }\end{array}$ & $\begin{array}{l:l}\text { got }<=\text { have }>\text { (3) } & \text { need (VOS) } \\
\text { have (4) came off } & \text { comes (SOV) } \\
\text { coming down (2) } & \text { make (VOS) } \\
\text { tangle(d) up, see (3) } & \\
\text { hear, need, scare } & \\
\text { say, drop (2), draw } & \\
\text { play }\end{array}$ \\
\hline
\end{tabular}

\section{Notes}

a. 'Broken chair. I broken chair fix' (SOV). Examining a broken chair.

b. 'Mommy change me'. Request to have diapers changed.

c. 'Open door mommy' (VOS). Has just seen a mother with children open door and leave building.

d. E sets out to find F in airport, saying 'right back, mommy. Daddy get me' $<=$ I'll get daddy $>$.

Figure 10 
e. 'Take Christy beads' (VSO). After $\mathrm{C}$ takes away E's beads.

f. 'Pingpong balls me eat' (OSV). E eating meatballs.

g. 'Hit me Christy arm mines' (VOS). Complaining that $\mathrm{C}$ hit her on the arm.

h. 'Poppy (= pacifier) pinch me back there'. After gets finger caught in pacifier.

i. 'Read Mommy book' (VSO). To $\mathrm{C}$ whom $\mathrm{E}$ is pushing away; doesn't want $\mathrm{C}$ to interfere because $\mathrm{M}$ is reading to her.

j. 'Ride boat man' (VOS). E playing in bath with toy man who is riding on a whale.

k. 'Close door me!' (VOS). After E closes a door.

1. 'Christy water turn off' (SOV). Upset after C turns off water.

Figure 10. Syntactic mapping of verbs with prototypical agent-patient arguments vs. 'other' two-argument verbs in Eva's speech

both a theme and a location or goal argument (see also Figure 5), and it is also the week in which SVO strings with other transitive verbs like see, read, and hold first occurred. There is thus no advantage for prototypical agent-patient verbs: as soon as Christy was ready to handle a verb plus two arguments, she could manage a variety of verb types equally well. ${ }^{9}$ Word order was generally correct for two-argument strings, with four exceptions for prototypical agent-patient verbs and five for 'other' verbs up through age 1;11 [weeks $3 \& 4$ ] (after this age, no more SVO ordering errors were observed). The absence of relative facilitation for prototypical agent-patient verbs means that if the syntactic treatment of verbs with theme and $\mathrm{L} / \mathrm{G} / \mathrm{S}$ arguments was learned without help from linking rules, as indicated by the results in section 3.2 , then so was the syntactic treatment of prototypical agent-patient verbs.

Although word order was generally correct for two-argument strings in Christy's corpus, single-argument strings consisting of a verb and a prototypical patient argument were often misordered. In fact, in the twoweek period of $1 ; 11$ [weeks $1 \& 2$ ] - two months after the onset of twoargument strings with prototypical agents and patients - the number of incorrectly ordered (OV) strings with prototypical patients was two-thirds that of correctly ordered (VO) strings (12 tokens, 8 verb types vs. 19 tokens, 12 verb types). ${ }^{10}$ In striking contrast, among 'other two-argument verbs' there were 22 tokens of correctly ordered VO strings ( 16 verb types) and not a single token of incorrect OV order.

Mapping problems centering on prototypical agent-patient strings are also seen in Eva's data, and more dramatically than in Christy's. Like Christy, Eva began to produce two-argument strings with prototypical agent-patient verbs at the same time that two-argument strings involving 'other' verbs appeared $(1 ; 8$ [weeks $1 \& 2])$, with theme and L/G/S verbs following immediately in the next two-week period. Strikingly, for the six-week period from $1 ; 8$ [weeks $3 \& 4$ ] to $1 ; 10$, Eva made many more 
ordering errors with prototypical agent-patient verbs than with verbs of other kinds (see Notes to Figure 10 for some examples). Specifically, during this period 12 out of 20 , or $60 \%$, of the strings with prototypical agent-patient verbs were misordered. In contrast, only eight out of 39 , or $21 \%$, of the strings with 'other' verbs were misordered; note that of these eight, five involved agent-patient verbs, albeit 'nonprototypical' ones (read, ride...), and the rest involved VSO errors with come, which, as noted in note 5, have a model in adult English. The greater accuracy of mapping with verbs that do NOT involve agents and patients is thus striking. Among single-argument strings, there were also many more ordering errors (both OV and VS) with prototypical agent-patient verbs than with 'other' verbs. In short, far from being facilitated relative to 'other two-argument verbs', verbs with prototypical agent and patient arguments seemed to provide Eva with special mapping difficulties.

These findings are not unprecedented. In an analysis of order patterns in children's two-word utterances in English and other languages, Braine (1976: 25, 67-68) noticed many verb-object ordering errors, especially in utterances expressing causal events. In discussing this, he proposed that children may initially have trouble deciding on the status of the object acted on in a causal event: is it a patient, or is it an actor vis-à-vis its own motion or change of state? Confusion of this type is problematic for the hypothesis that children's acquisition of constructions with agents and patients is facilitated by innate linking rules, since events expressing causal relationships are considered by virtually every theorist to represent highly prototypical agent-patient relationships. ${ }^{11}$

In sum, these data suggest that children may have the most severe problems in mapping thematic roles onto syntactic positions with precisely those verbs for which mapping should, by hypothesis, be the easiest if language learners are guided by innate linking rules: when the arguments are prototypical agents and patients. Either children have more trouble identifying agent and especially patient participants in events than other kinds of participants, or they are less successful in using linking rules that apply to agent and patient arguments. Either way, this outcome goes counter to the hypothesis that knowledge of linking-rule hierarchies is innate.

\section{Interpreting these findings}

In section 3.2 and 3.3 I have shown that it takes children no longer to assign syntactic functions to the arguments of verbs that are linked noncanonically than to those that are linked canonically, holding their 
thematic roles constant and regardless of which way canonicality is characterized. Conversely (section 3.4), it takes no LESS time to map prototypical agent and patient arguments than two arguments of other kinds - in fact, for some children, at least, it takes even longer. How shall we interpret these outcomes?

Reacting to an earlier draft of this paper, Pinker (1989) suggests that the data might come from too early a period of language development to be relevant:

The earliest usages' of verbs in this age range are often quite restricted, concrete, or context-bound. The more schematized verb meanings that play a role in linguistic generalizations are only in evidence several months after the first usages. ... Thus there is at least a possibility that some of these very early uses may reflect not the lexicosemantic structures and argument structures that theories of linking rules apply to, but some kind of preliminary, relatively unanalyzed placeholder for a word that is given a more abstract and structured semantic representation only later (1989: 286).

This argument, if correct, in effect vitiates most of the advantages claimed for crediting language-learners with innate knowledge of linking rules by Pinker (1984) and others. The data I have discussed do not represent isolated examples of word use or word combination. They come from the period during which the children were producing many sentences of two, three, and even four or more words and were clearly developing the basic phrase-structure rules of English (such as ordering of constituents), along with a sizable vocabulary of everyday verbs. It is therefore precisely the period during which proponents of innate linking rules, including Pinker (1984), have supposed that knowledge of linking rules would help learners-the most. If children must wait to apply their linking rules until they have come to a more complete analysis of the meanings of the relevant verbs, there is little need for them: phrase structure has already been acquired, and so has the correct syntactic handling of most of the basic verbs!

But Pinker (1989) also questions the relevance of the data presented in sections 3.2-3.3 for a deeper reason, 'one that applies regardless of the psycholinguistic status of the first usages' (1989: 286). Specifically, he observes that 'the predictions of acquisition order that Bowerman's data disconfirm are not consequences of innate linking rules in general, but of one theory of linking rules that is probably not viable anyway' (1989: 286-287). In his recent work, Pinker has rejected his earlier (1984) model of how linking works in favor of an alternative model, based on Jackendoff (1987, i.p.), Levin (1985), and Rappoport and Levin (1985), according to which ALL verbs are consistent with linking rules. If all verbs are 
consistent and there are no longer any noncanonical or 'marked' linkages, then data such as I have presented above seem to present no problem: 'Lack of consistent asymmetry in acquisition' order for verbs exploiting different sets of the available linking rules is exactly what the theory predicts' (Pinker 1989: 287).

It is important to recognize that the new approach buys conformity by all verbs to hypothesized linking rules at a certain price to a theory of language acquisition: when rules apply equally to all verbs, they provide much less precise guidelines for the semantic bootstrapping of phrase-structure rules and for predicting the subcategorization frames of newly acquired verbs. Pinker (1989) also realizes this: 'The simplicity and generality of [the new] linking rules ... place a corresponding burden on the learning theory for phrase structure and inflection ... and on the learning theory for semantic [that is, verb-argument] structures' (1989: 248-249). However, he believes the price is worth it for the help the new rules could provide with a thorny theoretical problem of later language acquisition: how, in the absence of negative feedback, children find the constraints on lexical rules specifying verb-frame alternations and stop making overgeneralizations like 'Don't giggle me' (causativization), 'I'm gonna cover a screen over me'(locative alternation), and 'I said her "no"" (dative alternation) (data from Bowerman 1982a, 1982b, 1988).

It is not yet clear whether Pinker's new approach is sufficient to explain how children stop making errors like these (see Bowerman 1988 for discussion). However, even if it can, there is no logical reason to assume that the linking rules Pinker invokes are innate. By the time the overproductivity of lexical rules is an issue, children are up to several years past the initial stages of language acquisition. They have therefore had plenty of time to learn linking regularities on the basis of linguistic experience. The search for evidence about whether knowledge of linking rules is INNATE must therefore concentrate on the earliest period of grammatical development.

\section{Are linking rules based on verb semantic structure innate?}

As noted, Pinker (1989) proposes that since all verbs are consistent with linking rules in the new theory, we should no longer expect any asymmetries in timing of acquisition. However, I think this assumption is incorrect. To see why - and to see how the theory that linking rules based on verb semantics are innate can still be tested by comparing the time of emergence and accuracy of argument mapping for strings of different kinds - we need to take a quick look at the basic tenets of the approach. 
In the new theory, thematic roles no longer form a fixed list that can be ordered in a hierarchy; instead, they are positions in 'decompositional' representations of verbs' meanings: for example, agent is the first argument of CAUSE, patient is the second argument of CAUSE (these are also represented as the first and second arguments of ACT), theme is the first argument of $\mathrm{GO}$ and $\mathrm{BE}$, location is the second argument of $\mathrm{BE}$, goal is the second argument of TO, and so on (Pinker 1989: 73; see also Jackendoff 1987 and i.p.). Each thematic role is associated with its own linking rule; for-example, agent is linked to subject, patient is linked to object, theme is linked to subject if that function has not already been assigned, otherwise to object. Arguments can bear more than one thematic role simultaneously, and semantic primitives like GO can receive metaphorical interpretations (such as state change) as well as spatial ones.

Since this model specifies that the way a verb's arguments are linked follows directly from its semantic representation, differences in the way seemingly closely related verbs (or alternative constructions involving the same verb) map their arguments must reflect differences in their meanings. For example, Pinker (1989: 211) attributes the mapping differences between John gave a book to Mary and John gave Mary a book to a difference in the causal structure of the two constructions that affects which argument is patient (and hence direct object): the former sentence means (rendered partially and very loosely) 'John acted on the BOOK, causing it to go to Mary', whereas the latter means 'John acted on MARY, causing her to have a book'. This approach is also applied to the difference between pour and fill in their choice of theme vs. goal as direct object (for example, 'act on WATER, causing it to go into a cup' vs. 'act on a CUP, causing it to go to the state of being full [with water]'), and it can be applied to the difference between English and Chechen-Ingush (see section 2.3.) in choice between theme and goal as direct object of hit, cut, cover, etc. (although, as Jackendoff i.p. discusses, the new linking theory still does not solve the problem of which NPs associated with a verb are actually arguments of the verb, and hence should be linked).

The seemingly opposite linkings of John HAS the book and The book IS on the table are more problematic, since they cannot be explained by reference to causal structure. To deal with this puzzle, Pinker (1989: 189) introduces a new semantic primitive, the state type HAVE, which has its own linking rule: its first argument is the possessor, and it links to subject position; its second argument is the thing possessed, and it links to directobject position. The English verb have expresses this meaning in pure form. It contrasts with be [in a location], which expresses a different primitive state type, $\mathrm{BE}$, whose first and second arguments are theme and location, respectively. ${ }^{12}$ 
If, as hypothesized, a verb's semantic structure and the mapping of its arguments are in perfect correspondence, a child with innate linking rules can predict correct mappings once he knows what a verb means. Some verb meanings, suggests Pinker, correspond directly to children's mental representation of the relevant events: 'the child can link verbs to these conceptual structures upon hearing the verb used in a situation exemplifying that structure' (1989: 254). Others are more ambiguous; for example, for pour and fill, is it the theme or the goal that should be understood as the entity causally acted upon?

Children should be able to resolve many meaning ambiguities by observing multiple uses of 'non-cognitively given' verbs in context, hypothesizes Pinker (1989: 254ff.). For example, they will discover that what is invariant for pour across a variety of uses is that the agent causes a certain type of motion in the theme (downward, in a coherent stream, etc.), with nothing implied about the end state of the goal. The invariant for $f i l l$, in contrast, is that the agent causes a certain state change in the goal, with nothing implied about the specific manner in which this change is effected.

In other cases, however, children may simply learn the mapping of the verb's arguments directly from adult speech. This is the same learning procedure - use of positive, distributional evidence - invoked in Pinker (1984) to explain how children acquire the mappings of noncanonical verbs (see section 3.1), with one important difference: under the new theory of linking rules, the child who learns a mapping directly from input must adjust his representation of the verb's meaning so that it is consistent with the mapping (Pinker 1989: 257).

Regardless of which technique the child uses to determine the mapping of 'non-cognitively given' verbs, it is clear that these verbs will require more effort than verbs whose meanings are cognitively transparent. Cognitively transparent verbs can in principle be mapped immediately (because there is only one candidate agent, patient, etc.); in contrast, 'something more' is needed for ambiguous verbs, and this will take extra time. If meaning ambiguities are resolved without reference to adult syntax, time is needed to observe and compare adult uses of the verb across contexts to extract the critical semantic invariances. And if they are resolved by direct observation of the correct mapping in adult speech, with subsequent adjustment of the verb's meaning to be consistent with the mapping, this also involves an extra step beyond direct mapping a step that, moreover, cannot take place until the child has already established a basic grammar of phrase-structure rules, as Pinker (1989: 257) also recognizes. This is because the child cannot notice that in adult speech a particular argument is the direct object (for example) and thereby 
infer that it must be the patient, until she has figured out which constituents are direct objects.

To test the hypothesis that the new-style linking rules are innate, we therefore need to compare strings with cognitively transparent verbs and more ambiguous verbs with respect to both time of onset and consistency of mapping. The best candidates for transparent verbs are those that express prototypical agent-patient relationships. According to Levin (1985), these are consistently transitive across languages, and they map their arguments in the same way (see also Croft 1987) (this is why Pinker [1984, 1989: 250] assigns them a key role in the semantic bootstrapping of phrase-structure rules). Much more variable in their mapping, both within and across languages - and therefore more ambiguous in their semantic structure and in need of special learning procedures, according to the logic of Pinker's approach - are 'verbs of emotion, cognition, desire, expectation, achievement, authority, and perception' (Levin 1985: 13; see also Nichols 1975). To these we may add possessive constructions, since languages differ in whether they have a special verb like have, which maps the possessor into subject position and the possession into directobject position, or instead use a locativelike construction with a verb like $b e$, in which the possession (thing located) is subject and the possessor (location) is oblique object (Lyons 1967). ${ }^{13}$

From the analyses presented in section 3.4 (see Figures 9 and 10) it is already clear that, in the early grammatical development of my two subjects, there was no advantage for prototypical agent-patient verbs over verbs of possession like have and got, verbs of perception like see and hear, verbs of desire like want and need, and verbs of emotion like scare, like, and hurt. Two-argument strings with verbs from all these categories emerged simultaneously, and the children in fact made more argument-ordering errors - which could reflect either incompletely established phrase-structure rules or incorrect linking - with prototypical agent-patient verbs than with verbs of other kinds. This evidence goes squarely counter to the hypothesis that knowledge of linking rules defined this time in terms of verb semantic structure rather than paired thematic-syntactic hierarchies - is innate.

\section{Are linking rules learned?}

We come back at last to a possibility raised earlier: if linking rules are not innate, are they learned? In principle, it is not necessary for children to learn them: they could become fluent speakers simply by acquiring each verb's subcategorization frame individually onuthenteacis of 7 direct 226 
positive evidence, never noticing overarching regularities such as 'agent is subject'. But, as Brown (1973: 122) observes, 'there is a potential economy or advantage in forming [such] abstraction[s]', so it seems plausible that even if children do not start out with a knowledge of linking regularities, they do end up with it (see Foley and Van Valin 1984).

One line of evidence that such learning takes place is that, as noted earlier, children use canonical mappings at least for agents and patients in making sentences with spontaneous or experimentally introduced novel verbs. In this section I present an additional type of evidence: linking overregularizations, or errors in which children 'correct' verbs whose mappings go counter to a learned linking pattern.

In the early phases of grammatical development, as I noted earlier (section 3.1), children make no errors in which they regularize verbs hypothesized to involve noncanonical linking. This seemed at least mildly surprising under the assumption that children have an innate sense of canonical mappings. Later, however, they begin to make certain errors that might reflect learned linking rules; these include several 'late' or 'reorganizational' error patterns that I have described in previous research based on diary data from my daughters (for example, Bowerman 1982a, 1982b, 1988).

The lateness of the errors is important for the claim that the underlying pattern is learned rather than innate. When children make errors on the basis of a pattern that is clearly learned, such as past tense -ed or plural $-s$, they do not do so initially, but only after a period during which exemplars of the pattern are learned piecemeal and used correctly. 'Canonical' linking errors that begin only months or years after the early stages of language development are thus easy to interpret as overregularizations of a learned pattern. In contrast, they are difficult to account for under the hypothesis that knowledge of linking is innate. In particular, note that if, as Pinker (1984) proposes (see section 3.1), children's sense of canonical mappings is so easily overriden by evidence in the input for noncanonical mappings that we need expect no 'default' mapping errors in the early phases of acquisition, there is no reason for children to begin to produce such errors later.

Certain candidate linking overregularizations are ambiguous: they might be due to the overgeneralization of learned linking rules, but they can also be accounted for in terms of the child's formulation of a lexical rule that predicts new syntactic frames for verbs of a certain type. Consider, for example, errors like 'I'm gonna cover a screen over me' (= cover myself with a screen) and 'Can I fill some salt into the bear?' (= fill the bear [a salt shaker] with salt). These might occur because, after 
exposure to many verbs, the child develops a sense that if a verb is followed by both a theme and a goal argument, it is more usual for the theme to be the direct object (Bowerman 1982b; note that this is consistent with the canonical linking pattern shown in Figure 1). Alternatively, however, such errors might reflect the child's formulation of a lexical rule that predicts a new syntactic frame for locative verbs on the basis of observed alternations like John sprayed paint on the wall vs. John sprayed the wall with paint (Pinker 1989).

Inducing and overgeneralizing a lexical rule involves learning a pattern, of course, but it is not the pattern we are interested in at the moment. What we need is evidence that children can become sensitive to a statistically predominant linking pattern REGARDLESS of whether they know any verbs that alternate between this pattern and some other less dominant pattern. One set of late errors in my diary data does have the properties we are looking for: they are suggestive of learned linking rules and they cannot be 'explained away' as due to a lexical rule. These errors involve so-called psych verbs or mental verbs.

Mental verbs take two arguments, often termed experiencer and stimulus. It is well known that there is extensive variation both within and across languages in whether the experiencer or the stimulus is linked to subject position; compare Mary liked John's present with John's present pleased Mary. This variation has led to differences of opinion among theorists attempting to establish universally valid definitions of canonical linking: for example, Grimshaw (1987) considers the experiencer-subject pattern as canonical, whereas Carrier-Duncan (1985) and Pinker (1984) give this honor to the stimulus-subject pattern (they interpret the experiencer metaphorically as a goal or location and the stimulus as a theme). Theorists for whom linking follows from verb semantics explain the mapping variation among metal verbs by reference to differences in the causal and/or aspectual structure of verbs of the two types (for example, Croft 1987; Pinker 1989; see also Talmy 1985). For example, verbs that take stimulus subjects often specify a state change in the experiencer caused by the impingement of the stimulus (examples: please, excite, bore, surprise, scare ...), whereas verbs that take experiencer subjects often express a 'noncaused' mental state of the experiencer or a tuning of the experiencer's mental activity toward some stimulus (examples: like, need, enjoy, hate, fear, think, know ...).

Talmy (1985) proposes that although all languages may have some verbs of both types, they differ as to which type predominates. For example, Atsugewi, a Hokan language of northern California, has almost exclusively verbs with experiencer subjects. English, in contrast, 'seems to favor lexicalizing the Stimulus as subject. While some of its most 
colloquial verbs (like, want) have the Experiencer as subject, the bulk of its vocabulary items for affect focus on the Stimulus' (1985: 99). Talmy illustrates with an extensive list of English verbs of each type, and also adduces evidence that the stimulus-as-subject pattern has been growing stronger in English over time.

With Talmy's proposals in mind, let us have a look at children learning English. For the first several years of language development, the two children of my diary study mapped the arguments of mental verbs of both patterns completely correctly. However, beyond age 6 (Eva) and 8 (Christy), they began to make occasional mapping errors; for example, these 'late' errors in the mapping of verbs with experiencer and stimulus arguments:

1. C 8;7 I have an idea, but it won't APPROVE to you or daddy. $<=$ you and daddy won't approve of it. $>$

2. C 9;0 How does 'Hurly Girl' FANCY you? $<=$ how do you fancy/ like...>

3. C 10;8 I must have been allergic to that 'cause it REACTED more on me. $<=I$ reacted more to it; after $\mathrm{C}$ chokes on hot pepper flakes in a restaurant. $>$

4. E 6;2 It didn't MIND me very much. $<=$ I didn't mind it/it didn't bother me; with reference to a storm the night before. $>$

5. E 6;6 I saw a picture that ENJOYED me. $<=$ that I enjoyed. $>$

6. E 6;8 You know what PICTURES me uncle? < = what I picture as an uncle; how I picture an uncle looking?>

7. E 7;6 She doesn't PICTURE to me like a 'Harrietta'. Does she to you? $<=$ I don't picture her as a...; with reference to a friend whose middle name is 'Harrietta'. $>$

8. E 8;10 I am very FOND. Everyone's fond of me. I am very fonded. $<$ Note that ' $\mathrm{I}$ ' is stimulus, 'Everyone' is experiencer. $>$

9. C 7;0 Don't do that! I don't APPEAL to that! <M: That doesn't appeal to you?> $\mathrm{C}$ : No! <After $\mathrm{M}$ tickles $\mathrm{C}$ under the chin.>

Almost all the errors involved treating a low-frequency experiencersubject verb according to the stimulus-subject pattern (examples 1-8) that is, the pattern that, according to Talmy, predominates in English. Very occasionally, the error went the other way - a stimulus-subject verb was used in the experiencer-subject pattern (example 9). This distribution of error types is reminiscent of an asymmetry found among morphological overregulations: most errors involve the overgeneralization of a statistically dominant pattern (for example, bringed), but a few involve the extension of a minor pattern (for example, brang). 
It is unlikely that errors like these result from a learned lexical rule that projects new argument frames for mental verbs, because there is almost no model for this: very few mental verbs of English can appear in identical form in both patterns (an exception is grieve). Semantically similar words in the two patterns are typically related either through suppletion (for example, It FRIGHTENS me vs. I FEAR it) or through verb-to-adjective derivation, for example, It FRIGHTENS me $\rightarrow$ I am FRIGHTENED of it (subject switches from stimulus to experiencer); $I$ HATE it $\rightarrow$ It is HATEFUL to me (subject switches from experiencer to stimulus) (Talmy 1985). In light of this, I propose that the most plausible explanation for the errors is that they reflect the child's acquired sensitivity to the statistically preponderant pattern according to which stimulus is subject and experiencer is direct or oblique object.

\section{Conclusions}

In this paper I have tested the hypothesis that children have an innate knowledge of rules linking thematic roles to syntactic functions against the alternative hypothesis that linking regularities are learned on the basis of linguistic experience. Two different approaches to linking were considered: one according to which linking rules are specified by paired hierarchies of thematic roles and syntactic functions, and the other according to which linking is a function of verb semantic representation. Regardless of which theory of linking we adopt, evidence concerning the timing of acquisition of verbs of different kinds and the accuracy with which their arguments are mapped is inconsistent with what we should expect under the assumption that knowledge of linking is innate. This outcome constitutes a serious challenge for any theory of language acquisition that invokes innate knowledge of canonical mappings to bootstrap the child into syntax.

If linking rules are not innate, they would not necessarily have to be acquired, since children could simply learn the syntactic handling of each verb individually from the input. However, children do seem to analyze their lexicons for linking regularities that apply across classes of verbs. In this study I have presented one line of evidence for this learning process: years beyond the early stages of grammatical development, children begin occasionally to overgeneralize a statistically predominant linking pattern for mental verbs of English to verbs that are exceptions to it.

Received 15 February 1989 Max Planck Institute for Psycholinguistics Revised version received 


\section{Notes}

* Earlier versions of this paper were presented at the 12th annual Boston University Conference on Language Development, October, 1987, and the Max Planck Institute's conference on 'The Structure of the Simple Clause', November, 1987. I am grateful to Soonja Choi and Eve Clark for comments on previous drafts, and to Soonja Choi for information on the expression of possession in Korean. Correspondence address: Max Planck Institute for Psycholinguistics, Wundtlaan 1, 6525 XD Nijmegen, The Netherlands.

1. See Pye (this issue) for an insightful discussion of various proposals that have been made about grammatical relations in putatively syntactically ergative languages. Pye himself ends up rejecting the idea that there are any languages with a fundamentally ergative syntax (as opposed to languages with one or more ergative construction patterns), which allows him to retain Pinker's (1984) semantic-bootstrapping hypothesis to account for the acquisition of phrase-structure rules.

2. Foley and Van Valin (1984) do invoke a universal linking hierarchy in their theory. However, this does not indicate the linking of thematic roles to syntactic functions but instead specifies 'more marked' vs. 'less marked' associations between roles like agent, theme, and location and the 'macro' semantic roles of 'actor' and 'undergoer'. It is the linking of the macroroles to syntax that the child must learn, according to Foley and Van Valin.

3. It is unclear to me whether verbs like fall[ [down], spill, and drip should be included in this category for purposes of testing whether children have innate linking rules that specify the canonical positioning of theme and L/G/S arguments. Although these verbs often appear with a locative or goal argument in adult speech (as in 'He fell on THE FLOOR'; 'Ice cream is dripping on MY PLATE'), they do not SUBCATEGORIZE this constituent (sentences without it are perfectly acceptable), so the linking-rule hypothesis does not apply to it. However, it is not obvious whether children are able to decide immediately whether a $\mathrm{L} / \mathrm{G} / \mathrm{S}$ argument that is semantically compatible with a verb is subcategorized by it or not (see discussion in section 2.2). I have therefore included them in the following analysis. Whether or not they are included in fact makes no difference to the outcome. Readers who consider them irrelevant can simply disregard them in Figures 5 and 6.

4. All but one of the single-argument utterances before this point involve the same verb, fall[down]. For reasons discussed in note 3 , this verb is of uncertain relevance. In any event, the utterances do not form part of a broader pattern.

5. Relevant for verb-theme-goal errors with come, like 'Comes car mommy' while the child pushes the car toward mommy, are sentences like 'Here comes the car [to mommy]'. The single error with have, 'Have Christy vitamin pill?', may have been influenced by the use of have as an auxiliary in yes-no questions such as 'Has Christy got a vitamin pill?'

6. Pinker (1984) recognizes that, in principle, his linking-rule theory predicts that children should find prepositional constructions easier, but he notes that 'the developmental evidence is far from straightforward' (1984: 398). In particular, he finds examples of both the prepositional and the double-object construction with verbs of giving and communicating from an early age in data from Brown (1973) and Bloom et al. (1975).

7. I have also included cut, hit, and cover in the 'prototypical agent-patient verb' category, despite my cautions in section 2.2 , both because many researchers have considered them to be prototypical and because the agent clearly acts in a salient way on some 
patient, even though the construal of this patient's identity (theme vs. goal) varies across languages. I have also included kick, although in some languages its translation equivalent takes an oblique rather than a direct object (as in kick TO something). This is because an object is clearly impinged upon, and it is impossible to tell whether children learning English intend any distinction between direct and oblique objects at this stage since they do not use prepositions yet. Readers who disagree with these or any other classifications can simply disregard or mentally reposition the disputed entries in the tables; the overall outcome will not be affected.

8. Excluded from subtypes (1) and (2) of the 'other two-argument verb' category are utterances with a self-referent subject NP produced when the child was attempting to gain control over the object specified by the direct object NP, as in 'I read/see/have/ need book' while trying to wrest the book from the grasp of another. This is because Budwig (1986) presents evidence that children may regard the subjects of such strings as agentlike. Also excluded from both the 'prototypical agent-patient verb' category and the 'other two-argument verb' category were utterances involving fixed frames like 'I VERB-it' and utterances with the hard-to-classify 'proto-verb; do, as well as direct and partial imitations and self-repetitions.

9. One-argument strings with prototypical agent-patient verbs did emerge somewhat earlier than those with 'other' verbs, but word order was unstable, especially for combinations with patient arguments.

10. In comparing $\mathrm{OV}$ and VO order for prototypical agent-patient strings, I disregarded OV utterances with verbs like open and break in contexts in which adults might use these verbs intransitively, such as 'egg broke' just after someone breaks an egg. However, this judgment very rarely had to be made; the overwhelming majority of OV errors in Christy's and Eva's speech involved verbs that are exclusively or almost exclusively transitive in adult speech, as in 'grass cut', 'milk drink', and 'string pull'.

11. This confusion is also problematic for the hypothesis that 'prototypical transitive events' play a privileged role in early grammar construction by providing a core meaning complex with which children initially associate canonical grammatical properties like basic word order and case markers (Slobin 1985).

12. This approach may seem to solve the problem by brute force (note that in principle, any number of completely arbitrary thematic-syntactic mappings could be said to conform to a postulated set of linking rules if we are willing to multiply the repertoire of semantic primitives enough and provide each one with its own linking rules). However, Pinker does try to justify the new primitive, HAVE, on various grounds independent of its usefulness in rendering have a canonically linked verb.

13. Pinker (1989: 254) suggests that the meaning of have (that is, the HAVE-state semantic primitive) corresponds to children's nonlinguistic way of conceptualizing possession, and that, in consequence, the mapping of possessor to subject and object possessed to direct object should follow automatically. This seems unlikely, however, since if possession is inevitably conceptualized as a HAVE state, serious mapping errors would be made by children learning languages like Finnish and Korean, which encode possession like location ('BE state') (Fin. Meri-llä on kynä 'Mary-AT/ON is pencil (NOM.)'; Kor, Mary-eykey yenphil-i itta 'Mary-LOC. pencil-SUBJ is', 'Mary has a pencil'). In Finnish, at least, such mapping errors have not been observed (Toivainen 1980). It also is unlikely that children could learn whether possession is encoded as a HAVE state or a BE state - and hence which linking rules should apply - by homing in over time on the 'meaning' of the verb in possessive constructions in their language. This is because it is unclear that there is any meaning difference beyond what is supplied by the mapping of arguments (even Pinker [1989: 189] suggests that "cogni- 
tively, the HAVE state is simply the inverse of the BE state, treating the location, rather than the locatum, as the "logical subject"). It therefore seems most plausible that children learn the mapping of possessors and items possessed by direct observation of possessive constructions in adult speech.

\section{References}

Berwick, R. C. (1985). The Acquisition of Syntactic Knowledge. Cambridge, MA: MIT Press.

Bloom, L., Lightbown, P., and Hood, L. (1975). Structure and variation in child language. Monographs of the Society for Research in Child Development 40 (2) (serial no. 160).

Bowerman, M. (1973). Early Syntactic Development: A Cross-Linguistic Study, with Special Reference to Finnish. Cambridge: Cambridge University Press.

-(1976). Semantic factors in the acquisition of rules for word use and sentence construction. In Normal and Deficient Child Language, D. M. Morehead and A. E. Morehead (eds.). Baltimore: University Park Press.

-(1982a). Evaluating competing linguistic models with language acquisition data: implications of developmental errors with causative verbs. Quaderni di Semantica 3, 5-66.

-(1982b). Reorganizational processes in lexical and syntactic development. In Language Acquisition: The State of the Art, E. Wanner and L. R. Gleitman (eds.). Cambridge: Cambridge University Press.

-(1988). The 'no negative evidence' problem: how do children avoid constructing an overly general grammar? In Explaining Language Universals, J. A. Hawkins (ed.). Oxford: Blackwell.

Braine, M. D. S. (1976). Children's first word combinations. Monographs of the Society for Research in Child Development 41 (1) (serial no. 164).

Bresnan, J., and Kanerva, J. M. (1989). Locative inversion in Chichewa: a case study of factorization in grammar. Linguistic Inquiry 20, 1-50.

Brown, R. (1973). A First Language. Cambridge, MA: Harvard University Press.

Budwig, N. (1986). Agentivity and control in early child language. Unpublished doctoral dissertation, University of California at Berkeley.

Carrier-Duncan, J. (1985). Linking of thematic roles in derivational word formation. Linguistic Inquiry 16, 1-34.

Carter, R. (1976). Some linking regularities. Unpublished manuscript, University of Paris VIII, Vicennes. (In On Linking: Papers by Richard Carter, Lexicon Project Working Papers 25, B. Levin and C. Tenny [eds.]. Cambridge, MA: MIT Center for Cognitive Science.)

Croft, W. A. (1987). Categories and relations in syntax: the clause-level organization of information. Unpublished doctoral dissertation, Stanford University.

Dixon, R. M. W. (1972). The Dyirbal Language of North Queensland. Cambridge: Cambridge University Press.

Foley, W. A., and Van Valin, R. D. (1984). Functional Syntax and Universal Grammar. Cambridge: Cambridge University Press.

Givón, T. (1984). Syntax: A Functional-Typological Introduction. Amsterdam: Benjamins.

Grimshaw, J. (1987). Psych verbs and the structure of argument structure. Unpublished manuscript, Brandeis University.

Guerssel, M., Hale, K., Laughren, M., Levin, B., and White Eagle, J. (1985). A crosslinguistic study of transitivity alternations. Papers of the Chicago Linguistic Society 21, 48-63. 
Jackendoff, R. S. (1972) Semantic Interpretation in Generative Grammar. Cambridge, MA: MIT Press.

-(1987). The status of thematic relations in linguistic theory. Linguistic Inquiry 18, 369-411.

-(i.p.). Semantic Structures.

Kiparsky, P. (1987). Morphology and grammatical relations. Unpublished manuscript, Stanford University.

Levin, B. (1985). Lexical semantics in review: an introduction. In Lexical Semantics in Review, Lexicon Project Working Papers, B. Levin (ed.), 1-62. Cambridge, MA: MIT Center for Cognitive Studies.

Lyons, J. (1967). A note on possessive, existential and locative sentences. Foundations of Language 3, 390-396.

Marantz, A. (1982). On the acquisition of grammatical relations. Linguistische Berichte: Linguistik als Kognitive Wissenschaft 80/82, 32-69.

-(1984). On the Nature of Grammatical Relations. Linguistics Inquiry Monograph 10. Cambridge, MA: MIT Press.

Nichols, J. (1975). Verbal semantics and sentence construction. Papers of the Berkeley Linguistics Society 1, 343-353.

-(1984). Direct and oblique objects in Chechen-Ingush and Russian. In Objects, F. Plank (ed.). New York: Academic Press.

Nishigauchi, T. (1984). Control and the thematic domain. Language 60, 215-260.

Ostler, N. D. M. (1979). Case-linking: a theory of case and verb diathesis applied to classical Sanskrit. Unpublished doctoral dissertation, MIT.

Pinker, S. (1984). Language Learnability and Language Development. Cambridge, MA: Harvard University Press.

-(1989). Learnability and Cognition: The Acquisition of Argument Structure. Cambridge, MA: MIT Press.

Rappoport, M., and Levin, B. (1985). A case study in lexical analysis: the locative alternation. Unpublished manuscript, MIT.

Rosen, C. (1984). The interface between semantic roles and initial grammatical relations. In Studies in Relational Grammar 2, D. Perlmutter and C. Rosen (eds.). Chicago: University of Chicago Press.

Schlesinger, I. (1971). Production of utterances and language acquisition. In The Ontogenesis of Grammar, D. I. Slobin (ed.). New York: Academic Press.

Slobin, D. I. (1985). Crosslinguistic evidence for the language-making capacity. In The Crosslinguistic Study of Language Acquisition, vol. 2: Theoretical Issues, D. I. Slobin (ed.). Hillsdale, NJ: Erlbaum.

Talmy, L. (1985). Lexicalization patterns. In Language Typology and Syntactic Description, vol. 3: Grammatical Categories and the Lexicon, T. Shopen (ed.). Cambridge: Cambridge University Press.

Toivainen, J. (1980). Inflectional Affixes Used by Finnish-Speaking Children Aged 1-3 Years. Helsinki: Suomalaisen Kirjallisuuden Seura. 
Brought to you by | Max-Planck-Gesellschaft - WIB6417 (Max-Planck-

Authenticated | 172.16.1.226

Download Date | 4/25/12 9:58 AM 